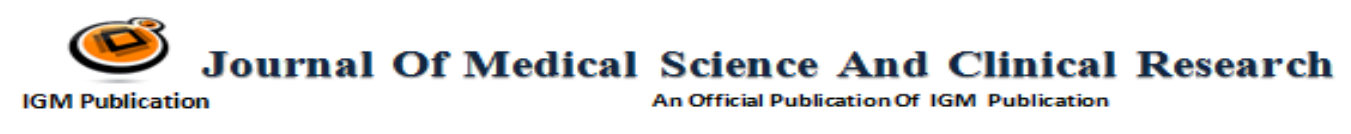

\title{
Modern Lifestyles and Its Effect on Well Being
}

\author{
Author \\ Nisha Devi \\ Asst. Professor (Physical Education) MCM D.A.V. College, Chandigarh
}

\section{Modern lifestyles and its effect on well being}

Modern lifestyle is highly competitive. The desire to be successful, rich and powerful in a short span of time has made each person materialistic. When we talk about modern lifestyle, it usually refers to the usage of the most up-to-date techniques, ideas and equipment's. It also denotes a current or recent style or trend. It is a peculiar and characteristic bundle of behavior including social relations, consumption, entertainment and dress. The behavior and practices with in modern lifestyle are a mixture of habits, conventions, way of doing things and reasoned actions.

In the hi-tech world of science and technology our lifestyles have totally changed. We have become used to all amenities and conveniences, which not only make our life easier and comfortable but reduced our physical efficiency, working on machines that to with lots of pressure and stress, affect our mental health, alertness and personal relations also.

Throughout centuries the leaders have recognized that not only the independence but also progress of country lies in its healthy, strong, mentally alert and well balanced people. Modern lifestyles and all the technological advances are for the upliftment of human being but every coin has two sides. Today with the advancement in technological developments, on the one hand we are enjoying lots of luxurious, on the other hand facing a lots of health problems.

\section{EFFECTS OF MODERN LIFESTYLES}

Following are some of the basic and burning problems which are effects of modern lifestyles.

1) Stress or tension in Children: The present system of education does possess elements which are efficient enough to develop the intellectual and talent potentials. Education produces scientists, engineers and doctors but in spite of becoming an expert in one's respective field by education, one suffers from enormous mental tension. Modern life is full of competitions and because of high competition in schools, children are under constant pressure. In today's society parents expect their kids to score more. They have no time to indulge in childhood games. Most of their time is spent in tuitions and schools, even in school and colleges, children have so much pressure of education that sometimes child is unable to cope up and commits suicide .Physical activities and games are stress buster but hi-tech gadgets like TV, Video, 
$\mathrm{CD}$ and computer games have made our children least interested in physical activities resulting in so many physical, mental and emotional problems.

2) Disturbed family relations: - In today's so-called modern world, growing at a fast pace, it is necessary, for each and every person to put in more and more efforts to prove himself. In the cut-throat competition and to maintain the standard of living, change in the joint family to nuclear family has taken place. Today with the increasing demand of working wives, women no more, are confined within the four walls of houses but are marching shoulder to shoulder with the male section in all walks of life. Moreover today's job or profession is highly demanding which requires women work for long hours leaving little or no time to look after their house or children. This effects their family life, resulting in divorce or clashes between husband and wife. There are ego clashes as no one has enough time to sort our petty issues amicably.

3) Health problems: - Modern lifestyle is detrimental to our health. Our habits have totally changed. We have changed our food habits also. The young generation is much interested in Chinese food or fast food instead of simple nutritious food. Fast foods like noodles, macaroni, pasta etc. are prepared by adding azenomoto which is carcinogenic. Various preservatives like acetic acid or other chemicals, flavors, coloring agents, are detrimental to our health.

A study conducted by P.G.I dietician has established that obesity is leading to several health hazards among children. The study was conducted over one year by Dr. B.N. Behera, on 64 obese children aged between 2 to 15 years. According to the study, child obesity is more common among urban nuclear families. Child obesity has been found to be three times more in urban children compared to rural kids." These children spent long hours watching TV, playing Video game (2-4 hours) and had family history of obesity" said Behera.

Another alarming fact that the study has revealed is that physical activity was grossly low in $92 \%$ of these obese children. These kids preferred eating junk foods in the form of pizzas, French fries, noodles, burgers, chips, sweets and high calories beverages. Interestingly the study found that most of these obese children were getting pocket money to buy eatables from school tuck shop.

Providing a solution to the problem, the study has emphasized the need for curbing consumption of junk food, besides discouraging a sedentary lifestyle to avoid obesity in childhood.

Total fitness in the need of hour as developments of scientific innovations has reduced our physical activities. TV, computer, video games are spoiling the health of our children. With all the medical facilities available today, physical problems are increasing. Besides obesity, cardiovascular diseases, cancers, high blood pressure, joint pains and spondylitis etc. are increasing because of modern lifestyle.

4) Tremendous stress at work place- Stress at work is relatively a new phenomenon of modern lifestyles. The nature of work has gone through drastic changes over the last century and is still changing. With change comes stress. Job/professional stress poses a threat to physical health. Job insecurity and high demand of performance especially in the time of corporate reorganizations, sometimes put unhealthy and unreasonable pressure on the employees. Increased workload and extremely long work hours and intense 
pressure to perform at peak levels all the time for some emoluments actually leave an employee physically and emotionally drained.

5) Less tolerance and violence: - It is believed that family is the main institution of the society which socializes its member for the expected behavior pattern but today with the change in lifestyles, utter materialistic outlook and busy life, the concept of joint family is no more prevalent in society. In nuclear families mostly mothers are working as a result young children are left to the care of baby sitters, nurseries, pre-school etc. Parents have no time to teach the young ones about societal norms and values which were transmitted to children by their grandparents in joint families in olden days.

Now, there is no one to check them. As a result they are more exposed to a lot many things which make them less tolerant and violent in behavior. The curiosity to watch porn, tasting alcohol or enjoying the ecstasy of drugs and impact of violence in movies like Gajini, Dhoom-2, Badmash Company etc-etc have affected the mindset of our children. Modern lifestyles and extra facilities have ruined the young generation.

6) Lack in norms and moral values:- India has a tradition of giving special regard and respect to parents. But today, in modern lifestyle it has been found that there is overall change in the status of parents. Exposure to the world of information and easy accessibility to latest technology, no doubt, developed new concept of social networking, where one can make as many as friends, in any corner of the world through various social networking sites like face book, orkut or twitter but youth are going away from their own people and their roots. Parents are the greatest pillars of support and help children in every filed to achieve their aim but they are not considered as important as they use to be earlier. Career and building contacts have taken the front seat. Old parents are abandoned by their children at the most difficult time of their life. Old age homes are also invention of modern lifestyles in Indian society. Now a day's children have no obligation towards their old parents. After working so hard throughout life, an old person looks for a comfortable life but they are neglected by their children, they were sent to old age homes. Old people experience mixed emotions of insult, hopelessness and anger. It not only leads to extreme depression but also instills extreme steps like suicidal tendencies in some cases. Busy modern life styles of today, have made people of the same family unattached and unconcerned. With latest technology you say hello or send text or enquire about others health but can't give happiness or joy which a person gets through healing touch and personal level.

7) Ecological pollution:- Man is an important component of environment. His efforts for economic development have created environment problems. The man has changed his life style, with new trends the household have curtains, carpets, rugs, sofas, furniture and beautiful potted plants, which are source of pollutants as they provide place for the growth of certain microbes which causes allergies and respiratory problems. Microwaves, Mobiles, Colored TV, Refrigerator, air conditioner, hair drier and other electric gadgets have become common household items and these items release CFC's and harmful radiation which are detrimental to man's health and environment. Today, use of cosmetics is very common and its use is increasing day by day. Various chemicals 
are used in these cosmetics which play havoc on our skin.

Modern lifestyle is responsible for far reaching changes in atmosphere through his various activities like urbanization, industrialization and over exploitation of resources. Global warming and ozone depletion are the result of our modern lifestyles. Global environment is changing with the buildup of various gases in the atmosphere. These changes are detrimental to the health of man. The climate is changing. This change would mean hotter summers, cooler winters, rise as sea level(melting of ice and glaciers) and change in monsoon pattern etc. the consequences will be climatologically disaster.

\section{Conclusion}

The real happiness of life lies in living healthy and stress free life, happily in a health environment. There is a need to understand that modern lifestyle can provide us all luxuries but we can't get mental peace and satisfaction from them. New inventions can provide us latest techniques of surgeries and drugs but most of the health problem which we are facing today is also the result of our modern lifestyle. Because of style statement we can wear branded shoes of puma, Reebok, or Nike but can't walk for $2 \mathrm{~km}$ because modern life style has reduced our physical efficiency, for just a short trip to a nearby market we go by bike or car. Thus, we can say that modern life style no doubt has made our life more easy and comfortable but the sad part is, it made man's life sedentary and in active. Excessive proclivity for luxuries and utter materialistic outlook, over industrialization as well as busy life have made man's life more stressful and depressed with getting jobs and dreams for higher social status to be achieved at any cost. Now the need of the hour is to change the mindset of the parents, who give more importance to all the luxuries and money rather than good human quality and good health.

\section{Suggestions}

The most precious thing in this world is health. Now the scenario in this modern lifestyle is such that people know the ill effects of certain things that they are consuming but due to status symbol and style statement they blindly follow the modern trend. There are certain suggestions for the happy and healthy living which are as follows

1) Physical activities should be recommended for every person in the society

2) Implementing quality physical education program on regular basis by qualified teachers ensuring that all students have the opportunity to become physically literate.

3) Enhancing the leisure time activity.

4) In primary schools particular attention should be paid to the development of body nourishment and healthy practices

5) Physical Education program should be made effective by creating awareness among masses.

6) By investing in health and active society.

7) By motivating people to participate in physical activities

\section{References}

1. www.jainworld.com

2. Physical education and sports in a changing society pg 20,21,22

3. H.T LIVE Chandigarh, Tuesday, December 22, 2009.(obesity is more common among urban children as compare to rural ones).Study by DR .B.N.BEHERA.PGI DITECIAN 